\title{
DEMOCRACIA E RESISTÊNCIA NA GESTÃO URBANA DE FORTALEZA: UM OLHAR A PARTIR DO CICLOATIVISMO
}

Harley Sousa de Carvalho ${ }^{1}$ Rafael Mesquita F. Freitas ${ }^{2}$

\author{
DEMOCRACY AND RESISTANCE IN URBAN \\ MANAGEMENT OF FORTALEZA: A LOOK AT \\ CYCLOATIVISM
}

RESUMO: Trabalho destinado a estudar e compreender o papel do cicloativismo na gestão urbana de Fortaleza, mais especificamente na temática de mobilidade. São analisados os grupos Ciclovida, Ciclanas e Massa Crítica, buscando apresentar diferenças e semelhanças em sua estrutura, atuação, demandas e formas de diálogo com o Poder Público e os demais citadinos, bem como as tensões daí decorrentes. Busca-se através de uma investigação predominantemente sociológica ofertar uma compreensão da dinâmica de tais grupos e da política urbana para além dos discursos oficiais e das formalidades jurídicas, dando ênfase ao olhar de quem escolhe a bicicleta como seu meio de mobilidade urbana.

Palavras-chave: Gestão democrática. Cicloativismo. Ciclovida. Ciclanas. Massa Crítica.
ABSTRACT: This work intend to study and comprehend the role of the "cicloativismo" (bicycle advocacy) in the urban management of Fortaleza, more specifically about mobility. Will be analyzed the groups Ciclovida, Ciclanas e Massa Crítica, seeking out to present the differences and similarities in their structure, acting, demand and dialog with Public Power and other citizens, as well the tensions resulting. We aim trough a predominantly sociologically investigation offer a understanding of the dynamics of such groups and the urban politics beyond official discourses and juridical formalities, giving emphasis to the look of those who choose bicycle as their way of urban mobility.

Keywords: Democratic management; Bicycle advocacy. Ciclovida. Ciclanas. Massa Crítica.

\footnotetext{
${ }^{1}$ Mestrando em Ordem Jurídica Constitucional pela Universidade Federal do Ceará.

${ }^{2}$ Graduação em Ciências Sociais. Graduado em Estatística pela Universidade Federal do Ceará.
} 


\section{INTRODUÇÃO}

A Lei Federal 10.257 de 2001, autodenominada Estatuto da Cidade, buscou consolidar um novo paradigma para a política urbana brasileira, pautando-se, sobretudo, na busca por construir cidades em respeito à sua função social e do bem-estar dos habitantes tal como determinado pelo artigo 182 da Constituição Federal de 1988.

Para inaugurar novas perspectivas em matéria de planejamento urbano, o Estatuto previu, entre suas diretrizes, o estabelecimento de uma gestão democrática da cidade (art.2, II), compreendendo a participação da população e de associações representativas na formulação, execução e acompanhamento dos planos e projetos para o desenvolvimento urbano.

Porém, os desafios para a efetivação de uma gestão democrática são de tamanha profundidade que não podem ser superados apenas com alterações na legislação urbanística. Encontra-se especial dificuldade em localizar no Poder Público canais institucionais que permitam a efetiva participação e expressão da sociedade civil na elaboração das políticas urbanas, estando arraigada numa postura burocrática e autocentrada na própria administração pública que escapou dos recentes impulsos democratizantes (LOPES FILHO, 2010, p. 200), limitando-se a receber a investidura democrática por via eleitoral e, após a conclusão deste processo, atuar de forma apartada aos influxos mais populares.

Todavia, esse hermetismo do Poder Público cede muitas vezes aos grupos de pressão formados pelos setores economicamente mais fortes. A atuação de lobistas, pressão midiática, esquemas de corrupção e financiamento de campanha tornam-se ferramentas fundamentais para influenciar em um modelo de desenvolvimento urbano mais condizente com suas pretensões, sendo determinante o reconhecimento de tais fatores em análises científicas dos temas sociais e políticos (BONAVIDES, 2010, p. 460)

A compreensão desse quadro fático e normativo é necessária para situarmos e analisarmos as ações dos grupos cicloativistas em Fortaleza. Tais grupos, cientes dos graves problemas apresentados na cidade, buscam influenciar novas concepções de 
mobilidade, em sentido estrito, e de cidade, em sentido amplo, que historicamente foram ignorados por um planejamento urbano especialmente voltado para os meios de transporte motorizados. A atuação se dá por múltiplas frentes, desde associação juridicamente formalizada, que atua formalmente perante o poder público e que se depara com as dificuldades em dialogar com uma administração pouco aberta e transparente, até os grupos informais, focados em intervenções diretas e práticas de resistência, os quais convivem com reiteradas tentativas de criminalização da sua atividade.

A exposição se dará pela ordem cronológica dos movimentos. O primeiro coletivo será a "Massa Crítica", grupo não constituído juridicamente e responsável por ações mais incisivas e à margem das vias institucionais, estando em constante tensão com o Poder Público municipal. O segundo grupo é a "Ciclovida", associação juridicamente constituída que possui diversificadas formas de atuação que incluem a participação no Plano Diretor Cicloviário até realização de oficinas educativas sobre direitos e conscientização política dos usuários de bicicleta. Por fim, estudaremos as "Ciclanas" que adiciona ao debate da mobilidade urbana as demandas específicas de ciclistas do sexo feminino. Em comum, os grupos apresentam a persistência em romper com um status quo urbano, condutas essenciais para o estabelecimento de novas práticas e políticas para uma Fortaleza que, em conformidade com o disposto na Constituição Federal e com a Carta Mundial pelo Direito à Cidade, cumpra com sua função social.

Portanto, uma leitura dos movimentos cicloativistas será insuficiente caso sejam analisados exclusivamente a partir da lógica binária entre lícito e ilícito, o que resulta na criminalização de uma série de práticas de resistências de tais movimentos. Diante disso, faz-se de suma importância a abertura da ciência jurídica para um diálogo com os esquemas e instrumentos interpretativos das ciências sociais que poderão revelar novas perspectivas para análise do problema. Desta feita, este trabalho foca na compreensão dos grupos cicloativistas citados, de suas dinâmicas e como colaboram ou buscam colaborar com a gestão da política urbana municipal. O ordenamento jurídico, por sua vez, será estudado com a finalidade de oferecer o contexto normativo que envolve os temas ora investigados, não representando sua dogmática aspecto principal deste trabalho. 


\section{GESTÃO DEMOCRÁTICA E DIREITO À CIDADE}

Por que democratizar a política urbana? Essa é a primeira das questões que devemos compreender e responder para se obter uma adequada compreensão do tema ora investigado.

O espaço urbano é fruto de uma formação social (SANTOS, 2006, p. 70), ou seja, na cidade a pessoa constrói o ambiente em que irá desenvolver sua vida individual e comunitária, estabelecendo relações afetivas, sociais, culturais, políticas e econômicas que compõem as múltiplas dimensões da vida humana. Diante disso, não se pode compreender o bem-estar dos habitantes de forma dissociada de sua cidade (BOMFIM, 2010, p. 30), devendo-se trabalhar e analisar de modo integrado.

Contudo, embora haja uma intensa e inescapável relação entre a pessoa e sua cidade, nem a todos foi e é garantida a possibilidade de construir uma urbe que espelhe e acolha seus anseios. Pelo contrário, a formação do espaço urbano de Fortaleza é capitaneada pelos setores economicamente hegemônicos que estabelecem os principais traçados de nossas cidades (IPLANFOR, 2014, p. 22), relegando aspectos secundários e marginais ao Poder Público ou à formação espontânea. As cidades brasileiras, tão plurais em seus aspectos humano e cultural, são excludentes nos aspectos social, econômico e político apresentando um cenário de patente segregação que, na leitura de Milton Santos e Maria Laura Silveira, resultou de uma "drenagem dos recursos sociais para a iniciativa privada" (2006, p. 306).

Foi na tentativa de dar uma resposta jurídica e política à essa realidade que o Estatuto da Cidade estabeleceu como pilares da política urbana o direito à cidade e à gestão democrática, objetivando construir uma nova realidade socialmente mais justa e aberta para nossas cidades.

Com o direito à cidade quer-se significar o direito dos citadinos em terem uma cidade que atenda com sua função social, aí compreendidos os deveres de sustentabilidade, acesso à terra urbana, moradia, saneamento ambiental, infraestrutura, transporte, serviços públicos, trabalho e lazer (art. 2으, I).

Em complemento ao direito à cidade, a gestão democrática objetiva dar voz e força política aos segmentos tradicionalmente marginalizados nas discussões de planejamento 
de nossas cidades, como forma de contornar os efeitos degradantes da nossa urbanização precária. As necessidades da sociedade urbana deverão ser captadas democraticamente e não por meio de mentes iluminadas (SILVA, 2010, p. 108), buscando-se propostas de urbanização com menores custos humanos e sociais.

Cumpre lembrar, em correlação com o que é ora estudado, que os avanços democratizantes do direito urbanístico foram obtidos por meio da atuação e pressão de movimentos sociais e políticos que acolheram a bandeira da reforma urbana e do direito à cidade (SAULE JÚNIOR, 2007, p. 47-48). Logo, o próprio desenvolvimento da legislação dependeu largamente do engajamento da sociedade e sua pressão sobre os poderes constituídos, conseguindo inovações legislativas que fortalecem a base jurídica de sua atuação. Dito isto, podemos afirmar que o engajamento de movimentos sociais na política urbana não é apenas uma das diretrizes do Direito Urbanístico brasileiro, mas fator decisivo para a sua própria consolidação.

O impulso para a democratização da Política Urbana pode ser vislumbrado em todos entes federados. Na Constituição Federal de 1988, o art. 29, XII, prevê a participação de associações representativas no planejamento municipal. Na legislação federal, o Estatuto da Cidade estabelece modalidades de participação por conferências, audiências públicas, iniciativa popular de leis e projetos de desenvolvimento urbano (art.2으, II e art 43). $\mathrm{Na}$ legislação municipal de Fortaleza há, igualmente, inúmeras previsões de participação política, compreendendo desde a participação no Conselho Municipal de Desenvolvimento Urbano (Plano Diretor de Fortaleza, Lei Complementar n. 62, art. 290), participação na formulação da política de mobilidade urbana (LC 62, art. 35, XI) e em iniciativas populares de lei (art.5o da Lei Orgânica do Município) e de projetos urbanos (art.61 da Lei Orgânica do Município). Em outras palavras, esse arcabouço normativo impõe sobre o Poder Público o dever de democratizar a política urbana, não estando à disposição das conveniências políticas do gestor público (CARVALHO FILHO, 2009, p. 298).

Democratizar passa a ser visto com um objetivo mais amplo que a mera captação das necessidades da população, sendo indicado, igualmente, como meio necessário para a apropriação dos planos urbanísticos pela sociedade, concedendo-lhes força política e continuidade (IPLANFOR, 2014, p. 9). 
Atendendo especificamente ao tema da política de mobilidade urbana, podemos destacar alguns dispositivos legais que incluem o dever de democratizar sua elaboração e gestão. O artigo 7ํㅡ, inciso V, da lei 12.587 de 2012, coloca como objetivo da Política Nacional de Mobilidade Urbana "consolidar a gestão democrática como instrumento e garantia da construção contínua do aprimoramento da mobilidade urbana". Já o Plano Diretor de Fortaleza determina o "estímulo à participação da sociedade nas políticas públicas de mobilidade urbana" (art. 35, XI), o que indica, ao menos na dimensão normativa, uma abertura para a participação.

\section{CONTEXTO CICLOATIVISTA}

Para compreender o posicionamento e as ações do cicloativismo fortalezense é esclarecedor percebe-lo como parte de um movimento adaptado as particularidades locais, mas atrelado histórica e idelogicamente a um fenômeno de escala nacional e mesmo global.

Como caso paradigmático do cicloativismo, pode-se citar o exemplo holandês uma vez que este país europeu conta, atualmente, com mais de 20.000 quilômetros de ciclovias e é destaque mundial em termos de transporte urbano em bicicleta. Com $26 \%$ de todo o volume de tráfego feito por esta modalidade, há 18 milhões de unidades para seus 16 milhões de habitantes (EMBAIXADA HOLANDESA DE CICLISMO, 2016).

Porém, nem sempre a Holanda foi tão receptiva aos ciclistas.

Na década de 60 a preferência por veículos automotivos cresceu, assim como os acidentes de trânsito com vítimas. Estudos apontam que a taxa de acidentes passou de cerca de 1.000 fatalidades em 1950 para mais de 3.300 em 1971 (sendo mais de 400 crianças envolvidas), e, em 2014, após a massificação da bicicleta como meio de mobilidade, houve uma regressão para aproximadamente 500 fatalidades. (SWOV, 2015, p. 1-3).

Esse regresso histórico ao caso holandês se justifica pelo fato de que a Fortaleza atual, quanto à centralidade do carro como meio de mobilidade urbana, não se diferencia tanto das cidades holandesas dos 1960. A inclusão da bicicleta como meio de transporte a ser considerado nas políticas públicas é recente e tem acontecido, assim como no caso 
europeu, através da pressão popular. Até a emergência do cicloativismo, a bicicleta era ignorada como um modal de mobilidade urbana, o que pode ser evidenciado, por exemplo, pelo fato do Instituto de Pesquisa e Estratégia do Ceará (IPECE, 2013), ao traçar o perfil municipal de Fortaleza, quanto ao tema Mobilidade Urbana, em 2013, não fez qualquer citação ou análise em relação a bicicleta.

É justamente com a finalidade de romper com a invisibilidade política e social do ciclista urbano que o cicloativismo, através de variadas estratégias e linhas de atuação, emerge como elemento importante e pulsante nos debates das urbes brasileiras, podendo ser definido como:

(...) um sistema de ideias que reconhece e investe na atividade, no protagonismo, na participação política em favor da inclusão da bicicleta com segurança e conforto no sistema de mobilidade urbana. Seus adeptos não compõem um bloco uniforme, mas suas diferentes abordagens e concepções, através de diversos canais de relacionamento e de debate, levam ao amadurecimento do conjunto através da amarração de compromissos e da qualificação de métodos. (SOARES et al., 2015, p. 8).

Diante da complexidade e dinâmica do cicloativismo, sua compreensão no contexto local exige uma análise pormenorizada dos grupos que compartilham desse sistema de ideias, embora divirjam sobre os meios de atuação e a ênfase dos discursos.

\section{CICLOATIVISMO EM TRÊS ATOS}

Os grupos pesquisados possuem, cada um, dinâmica peculiar de atuação. Apresentou-se como característico dos movimentos propagados por estes coletivos serem bastante interativos e autoconfiguráveis em suas demandas e modos de operar, fatores que levam a uma estrutura menos hierárquica e a maior participação dos membros (CASTELLS, 2013, p. 25). Nota-se múltiplas expressões de necessidades e desejos evidentes nestes movimentos, o que resulta em formação de grupos que atuam com funções diferentes, mas que convergem para um tema predominante que culmina na pressão e apelo a novas formas de deliberação, representação e tomadas de decisão políticas (CASTELLS, 2013, p. 30), qual seja: o uso da bicicleta como meio de transporte urbano. Porém questões como convívio urbano, segurança, cidadania, representatividade, economia, sustentabilidade e gênero caracterizam e complementam a luta destes ativistas. 
O escopo deste trabalho não é aprofundar as formas de validação e estruturação de poder inerentes a cada um dos grupos, o que acreditamos ser objeto de pesquisa que poderia ser aprofundado em outros estudos. Intenta-se, aqui, compreender como o cicloativismo em Fortaleza, tomando como casos exemplares as ações dos grupos adiante estudados atuam para tornar relevantes ao poder público suas demandas e por quais meios acontece este diálogo, ou mesmo onde é possível notar sua ausência.

\subsection{Massa crítica}

Na década de 1990, em São Francisco, Califórnia, iniciou um movimento de ciclistas que encontravam em seu número a segurança que não sentiam sozinhos no cotidiano no trânsito. O movimento cresceu sem a presença de líderes e buscou manter essa formação em diversas outras cidades no mundo onde se desenvolveu.

O nome "Massa Crítica" se refere a uma expressão utilizada no filme Return of the Scorcher, de Ted White (1992), e alude a uma quantidade de ciclistas que sozinhos não conseguiam fazer uma travessia segura em meio aos carros, porém ao atingir uma "massa crítica", ou seja uma quantidade suficiente para se impor ao trânsito, forçavam sua passagem em segurança. O movimento reivindica o uso seguro da bicicleta como meio de transporte urbano, mas também enverada por outros temas como qualidade de vida, meio ambiente e críticas ao capitalismo e ao materialismo.

Em Fortaleza, o movimento surge em 2007, quando não havia ainda nenhum canal efetivo de diálogo com a prefeitura em relação a mobilidade urbana, em especial que considerasse a bicicleta como um meio de transporte, bem como a ausência de grupos de cicloativistas organizados (SOARES et al., 2015, p. 66). Entretanto, o que todos os grupos aqui estudados afirmam é que haviam muitos ciclistas em Fortaleza mesmo sem uma estrutura cicloviária, principalmente nas periferias, onde trabalhadores adotavam a bicicleta como um meio de transporte de baixo custo.

Os primeiros atos da Massa Crítica em Fortaleza foram as bicicletadas, surgindo as primeiras mudanças de formato em 2010, quando foi pintada uma ciclofaixa cidadã, pelos ativistas, na Avenida Antônio Sales. Entretanto a iniciativa não teve continuidade e no 
período de 2010 a 2012 não há outras ações registradas ou mencionadas (SOARES et al., 2015, p. 69).

A Massa Crítica Fortaleza passa a ser percebida novamente durante as eleições municipais de 2012, quando realiza campanha em prol da assinatura, pelos candidatos à prefeitura, da "Carta de compromisso com a mobilidade por bicicleta de Fortaleza". No primeiro semestre de 2013 participa de protestos para a retirada dos relógios de publicidade postos na ciclovia da avenida Bezerra de Menezes e em julho apoia a ocupação do Cocó, um movimento contra a construção de um viaduto nesta região, obra tida como favorável às opções motorizadas de mobilidade e ambientalmente insustentável.

Em agosto de 2013 os membros do grupo pintam três quilômetros de ciclofaixa da Rua Ana Bilhar, no bairro Meireles. Feita com baixo custo, estimado $\mathrm{R} \$ 350,00$, e por iniciativa popular, a ação teve grande repercussão, aumentada pelo embate com a Autarquia Municipal de Trânsito e Cidadania (AMC), que removeu a ciclofaixa no dia seguinte alegando "principalmente por não estar dentro dos padrões estabelecidos no Manual de Sinalização do Código de Trânsito Brasileiro", como afirmou Arcelino Lima, atual superintendente do órgão, que também considerou que a ação como "a violação de um bem público sem a prévia tentativa de diálogo com a AMC" (GRUPO PINTA CICLOFAIXA NA ANA BILHAR, 2013).

Como resultado desta ação, a AMC convocou os grupos de ciclistas urbanos ativos na época, Massa Crítica e a recém-criada Ciclovida, para debater sobre as implantações de ciclofaixas, porém, somente a Associação dos Ciclistas Urbanos de Fortaleza compareceu, pois, “a Massa não possui representantes e por isso não tem a função de dialogar com o poder público" (SOARES et al., 205, p. 69).

A ciclofaixa da Ana Bilhar foi oficializada no mês seguinte pela prefeitura. A Massa Crítica continuou pressionando a prefeitura pela ampliação da malha cicloviária com ações diretas como a pintura das ciclofaixas da Av. Antônio Sales, Av. Aguanambi, Av. Oscar Araripe, Rua Padre Anchieta, Rua José Cândido, Av. Bezerra de Menezes, Av. Presidente Costa e Silva, Av. da Universidade, Domingos Olímpio (faixa compartilhada com ônibus) e Av. Treze de Maio (MASSA CRÍTICA, 2016). 
Atesta a eficácia desta forma de atuação a constatação que parte das ciclofaixas pintadas por iniciativa deste coletivo foram posteriormente legalmente implantadas. $\mathrm{Na}$ luta por mobilidade urbana em Fortaleza, a Massa Crítica exerce forte e constante pressão sobre os órgãos do governo municipal, tendo demonstrado potencial para acelerar a execução de ações por parte dos órgãos da prefeitura, assim como também denunciar ausências.

O caráter de denúncia do movimento está presente, igualmente, na implantação das ghost bikes (bicicletas fantasma) nas avenidas da Universidade, Santos Dumont e Barão de Studart. A ghost bike consiste em "uma bicicleta toda pintada em branco e presa a um sinal de trânsito [ou poste] próximo ao local do atropelamento, acompanhada de uma pequena placa" (tradução dos autores, original presente em ghostbikes.org) e é uma ação presente em 29 países. Em Fortaleza, a primeira foi instalada quando Adler Menezes Duarte, 5 anos, faleceu em um atropelamento por uma van do transporte alternativo de Fortaleza, na Av. Santos Dumont, em 2013 (BICICLETA FANTASMA É..., 2013). Desde então outras bicicletas fantasmas foram instaladas, denunciando casos que, como esse, continuam a ocorrer. Nestas ações é comum ver apoio da Ciclovida e, mais recentemente, das Ciclanas.

O constante foco da Massa em ações diretas tem sido responsável por diversas notas e pronunciamentos dos representantes da prefeitura de classifica-la como vandalismo, como ocorreu em nota da AMC após a pintura das ciclofaixas das avenidas Joaquim Nabuco e Oswaldo Cruz. O ocorrido gerou uma nota de resposta do movimento onde se afirma que:

O foco do Massa Crítica com a demarcação de ciclovias, a priori, não é reduzir o engarrafamento. É democratizar a via pública e incentivar a utilização de um transporte mais ecológico, melhor para a saúde e menos egoísta, não somente para veículos motorizados, tendo em vista o espaço que ocupam nas vias. $\mathbf{0}$ Massa Crítica é adepto da ação direta. Acreditamos que é agindo que pressionamos o poder público a executarem nossas pautas. Não nos interessa os trâmites burocráticos relacionados a isso quando estes só veem para fazer com que as demandas populares não sejam atendidas. Já observamos, por inúmeras vezes que, quando os gestores querem e são coagidos a isso, eles fazem o que deve ser feito (COLETIVO PINTA CICLOFAIXAS EM RUAS DA ALDEOTA, 2014, grifo nosso). 
O contínuo embate da Massa Crítica com a AMC levou a criação informal da "Praça do Ciclista", através de intervenções urbanas na Praça Primeiro de Maio, localizada em frente à sede da autarquia, tais como instalação de paraciclo e colocação de faixas com mensagens de respeito ao ciclista (MASSA CRÍTICA DE FORTALEZA CRIA PRAÇA DO CICLISTA, 2014).

Não está dentre as propostas deste movimento dialogar com a prefeitura por vias institucionalizadas. Sob dizeres como "a prefeitura não faz, o povo faz", a Massa procura se apresentar como um movimento de autogestão popular em busca de qualidade de vida e que não se espera que vá ser provida pelo poder público. A postagem seguinte, feita na página do movimento na rede social Facebook, em um contexto de discussão de representação, evidência a postura do movimento:

É preciso que fique claro que ninguém representa ou fala pela Massa Crítica, nenhuma associação ou pessoa em particular. Ao contrário, quem se dispõe a dialogar com a Prefeitura, vai de encontro aquilo que a massa se propõe a ser: a Massa Crítica é um coletivo/evento horizontal, sem representantes, hierarquias ou líderes. Não dialoga com o poder, mas sim com a população. Parece que a prefeitura ainda não entendeu isso (MASSA CRÍTICA, 2016).

Pela proposital ausência de meios formais de representação ou que permitam que seus membros sejam identificados, importante pelo caráter ilegal de suas ações, os meios de captar as mensagens propagadas por este coletivo se restringem a participação em suas assembleias, onde são tomadas as decisões sobre onde e como agir, e pelas postagens feitas na página da Massa Crítica no Facebook.

Portanto propomos que a pergunta “Quem é a Massa Crítica?" seja substituída pelo entendimento de "Para que serve a Massa Crítica?". Sua organização é volátil, mas o

resultado de suas ações tem impacto bastante concreto em Fortaleza. Neste sentido, a prática social defendida é mais importante do que os indivíduos que a propagam.

\subsection{Ciclovida}

De dentro das assembleias da Massa Crítica surge, oficialmente, em março de 2013, a Associação dos Ciclistas Urbanos de Fortaleza, com a finalidade de "defender os direitos dos ciclistas e de contribuir para resolver os problemas de mobilidade de Fortaleza", tendo 
como um dos meios a "representação do interesse dos ciclistas perante os Poderes Públicos e a sociedade".

Em seu estatuto é definido que o órgão máximo da Associação é a Assembleia Geral, que pode ser convocada pelo presidente ou por um quinto de seus associados. Também é estabelecido neste documento que todos os associados deverão ter iguais direitos e deveres perante a Associação (CICLOVIDA, 2013). Na estrutura funcional da Ciclovida há uma hierarquia que não está presente de forma clara na Massa Crítica, e que é necessária para a formalização e representatividade de suas atividades. Porém, apesar de explicitada a diferenciação de cargos e funções, são garantidos direitos a todos os associados que permitam assumir qualquer cargo ou contestar ações tomadas pela diretoria.

Todas as decisões oficiais tomadas por este grupo são discutidas em assembleia ou através de fórum online (utilizando a ferramenta google groups), que permite a todos os associados que participem horizontalmente dos debates. As notas da Ciclovida são subscritas por seus representantes, geralmente o presidente da associação, porém sua redação é desenvolvida em ferramentas de edição de acesso livre aos associados.

Apesar de ter sido criada oficialmente em 2013, no ano anterior seus fundadores tiveram participação na elaboração da "Carta de compromisso com a mobilidade por bicicleta de Fortaleza", assinada por todos os candidatos à prefeitura municipal e que exerceu sua função de pressionar e dialogar com os órgãos municipais de forma a obter a garantia de direitos importantes aos cicloativistas. Carta semelhante havia sido assinada pelos candidatos à prefeitura de São Paulo no mesmo ano por iniciativa da Associação de Ciclistas de São Paulo, a Ciclocidade. A carta contém 10 medidas consideradas pelos ativistas como "fundamentais (...) para garantir a segurança dos ciclistas a uma melhor mobilidade para os fortalezenses".

Uma análise dos compromissos elaborados na Carta já indica meios de atuação cicloativista que seriam ocupadas posteriormente pela Ciclovida, diferenciando-se da estratégia adotada pela Massa Crítica. Enquanto a Massa Crítica procura ações diretas, sem necessidade de acordo com os meios institucionalizados, a Ciclovida busca assegurar instrumentos legais que garantam os direitos de ciclistas, inclusive garantindo a existência de ferramentas e mecanismos de diálogo com a prefeitura. Os cinco primeiros itens da 
Carta são bastante ilustrativos no sentido, pois tratam da elaboração e finalização do Plano Diretor Cicloviário de Fortaleza; destinação de parte do orçamento municipal para políticas públicas voltadas à mobilidade por bicicleta; criação de um setor na Autarquia Municipal de Trânsito e Cidadania (AMC) "especializado em políticas voltadas aos transportes não motorizados"; aplicação e fiscalização das leis do Sistema Cicloviário e institucionalização de canais de diálogo e informação sobre programas de interesse dos ciclistas (CARTA DE COMPROMISSO COM A MOBILIDADE POR BICICLETA DE FORTALEZA, 2012).

Além da função de intermediar a comunicação entre ciclistas de Fortaleza e Prefeitura, a Ciclovida também tem suas próprias ações que fomentam o uso da bicicleta como meio de transporte e embasam suas reivindicações.

Menciona-se, de início, a contagens de ciclistas que são feitas como forma de comprovar a presença de usuários deste modal, onde há necessidade de instalar vias e que, com a instalação destas vias, o número de ciclistas tendem a aumentar. Os membros desta associação também fazem verificação das condições das ciclovias, ciclofaixas e paraciclos instalados pela prefeitura e levam suas reclamações aos órgãos competentes.

Em 2013 a Ciclovida organizou a "Semana da Mobilidade", onde ocorriam palestras, debates, fóruns e ações educativas relacionadas a Mobilidade Urbana. Em 2014 e 2015 a semana foi expandida e o evento tornou-se o "Mês da Mobilidade", sendo responsável pela ampliação da rede de contatos dos ciclistas locais com o de outros estados, em especial do Nordeste. Todos estes eventos foram feitos com financiamento coletivo (SAKURABA, 2015).

Uma das atividades mais populares deste movimento é a Escola Bike Anjo (EBA), a qual, após adquirir maior participação de voluntários, passou a funcionar de forma independente da estrutura da Ciclovida. Esta escola está presente em outros dezoito estados brasileiros (BIKE ANJO, 2016) e busca ensinar a pedalar para crianças, adultos e idosos que desejem aprender.

\subsection{Ciclanas}

As Ciclanas começam como um coletivo em março de 2015 e carregam características tanto da Massa Crítica como da Ciclovida. Porém, diferenciam-se como uma 
espécie de autocrítica do movimento cicloativista em Fortaleza inserindo uma temática específica que não estaria sendo abordada adequadamente dentro dos demais grupos: trata-se da especificidade de problemas enfrentados por mulheres ciclistas, tanto em relação ao trânsito e políticas públicas, como em relação a decisões tomadas dentro dos movimentos de ciclistas urbanos.

Esta autocritica tem fundamental importância ao movimento ciclista por problematizar questões que ficavam em segundo plano ao se compreender seus integrantes como uma uniformidade lutando contra uma estrutura burocrática rodoviarista. Os problemas levantados mostram questões sobre assédio e machismo presentes dentro da sociedade cearense e que também surgem dentro do movimento. Em consonância com outros movimentos sócio-políticos latino americanos, o feminismo tem contribuído mostrando que há opressão dentro de grupos oprimidos (SANTOS, 2010, p. 104).

As discussões sobre machismo levantadas pelas Ciclanas têm influenciado a forma de agir da Massa Crítica e da Ciclovida. Em novembro de 2015, ocorreu o que a Massa Crítica chamou de "bicicletada feminista da Massa Crítica", culminando na pintura de uma ciclofaixa na Avenida Domingos Olímpio. E na última eleição de diretoria da Ciclovida, foi utilizado o critério de paridade entre membros do sexo masculino e feminino na gestão.

Nas ciclanas identificou-se um misto da estrutura adotada pela Ciclovida (quanto ao diálogo com o Poder Público e utilização de representações pontuais como meio de exercer suas atividades) e da horizontalização da Massa Crítica, que funciona como forma de anonimato para suas ações diretas e como princípio ideológico.

Aspásia Mariana, integrante das ciclanas desde sua formação, afirma que "nas Ciclanas esse termo 'associada' não existe, ele é burocrático e não nos representa". Porém a representação, necessária ao diálogo com as secretárias municipais, é aceita por este coletivo, que escolhe suas representantes pelo seu fórum eletrônico, na rede social Facebook. Não há hierarquia oficial entre as integrantes, porém são distribuídas funções de moderação como administração das redes sociais e articulação das reuniões presenciais. 
Em julho de 2015, foi promovido evento com a temática “Direitos e Deveres no Trânsito: A relação entre Pedestres, Motoristas e Ciclistas". Nesta mesa redonda estiveram presente membros de outros coletivos ativistas da cidade, como Ciclovida e Direitos Urbanos, bem como representantes de instituições públicas (da AMC e da Coordenadoria de Políticas Públicas das Mulheres da Secretaria de Direitos Humanos da Assembleia Legislativa do Ceará). Em setembro de 2015, durante o Mês da Mobilidade, evento iniciado em anos anteriores pela Ciclovida, as Ciclanas fizeram roda de conversa sobre emancipação feminina, com participação de Dillyane Ribeiro (advogada popular e ativista), Ivania de Alencar (agricultora líder da Ciclovida - Pentecostes) e Aline Cavalcante (cicloativista em São Paulo) (CICLANAS, 2015).

Segundo Aspásia Mariana, integrante do coletivo, outros atos encabeçados pelas Ciclanas são:

oficinas de mecânicas (mais de três, acho), cicloviagens, oficinas de stencil, costura, piqueniques, aulas de alongamento, encontro com fisioterapeuta, ações diretas, participação no percursos urbanos, colaboração com o Bike Anjo, pedal (sem batedor, sem obrigatoriedade de capacete e outros adereços que normalmente são obrigatórios em grupos de pedal (nightbikers)...tem mais coisa, certeza!

As Ciclanas têm participado dos debates com a Coordenadoria de Gestão Cicloviária em relação a implantação do $\mathrm{PDCl}$, o que diferencia este grupo da Massa Crítica, contudo não contam com uma estrutura formalizada tal qual a Ciclovida. Ressaltamos que, em decorrência de sua recente formação e pela ausência de pautas rigorosas, existe tendência a um maior desenvolvimento da identidade deste grupo, permitindo um dimensionamento mais preciso dos impactos de sua atuação e elementos diferenciadores em relação aos outros grupos.

\section{BALANÇO DA RELAÇÃO PREFEITURA E CICLOATIVISMO}

De acordo com o que foi exposto, tradicionalmente nossa cidade não foi contemplada com políticas de ciclomobilidade nem com efetivo diálogo entre Poder Público e usuários. Essa leitura se evidencia tanto pela ausência de legislação específica sobre o tema, lacuna suprida apenas em 2014 com a Política de Transporte Cicloviário e o 
Plano Diretor Cicloviário Integrado (Lei municipal 10.303), quanto pelo reconhecimento explícito do Instituto de Planejamento de Fortaleza a esse respeito (IPLANFOR, 2014, p.13).

Neste contexto, a atuação do cicloativismo foi determinante para romper com esse status quo da mobilidade urbana.

Pioneira na mobilização, a Massa Crítica, com sua forma mais espontânea de organização e manifestações mais incisivas, foi um movimento que contribuiu para tirar o poder público da inércia e os ciclistas urbanos da sua completa invisibilidade institucional (ausência de políticas públicas direcionados a eles bem como a não menção em documentos oficiais sobre o tema) e social (falta de respeito pelos demais usuários das vias públicas municipais), sendo por significativo período protagonista absoluto da luta dos ciclistas, havendo sensível evolução no tratamento do tema após o seu surgimento.

Porém, após avanço - ainda tímido - no diálogo e na abertura da gestão municipal, a atuação institucional se tornou mais interessante e atrativa, o que trouxe mais evidência para ações como da Ciclovida e das Ciclanas, que buscam a tradução de suas reinvindicações em políticas públicas de ciclomobilidade.

Constatou-se que há, hoje, alguns canais institucionais de participação como a coordenadoria de gestão cicloviária, que está inserida dentro da Secretaria de Conservação e Serviços Públicos, atuando de forma integrada ao PAITT (Plano de ações imediatas sobre trânsito e transporte). Além desse canal, há diálogo com o IPLANFOR (Instituto de Planejamento de Fortaleza) por meio dos Fóruns do Fortaleza 2040 (projeto que visa elaborar um plano mestre urbanístico para a cidade), e a Secretaria Municipal de Direitos Humanos. No caso dessa última, não há tanto uma obrigatoriedade institucional dessa secretaria em contribuir para o tema de mobilidade urbana, porém vem prestando contribuições para o debate em virtude de engajamento pessoal do Secretário da pasta, Sr. Karlo Kardoso, ou seja, é uma atuação mais personalista do que institucional, sem qualquer garantia de incorporação para seus sucessores. Entre suas colaborações, destacamos a campanha "Cidadania Sustentável - Para Viver a Cidade", que buscou estimular "o uso da bicicleta entre a população de Fortaleza como meio de transporte para quem precisa circular pela cidade" (SECRETARIA DE CIDADANIA E DIREITOS HUMANOS, 2015 , p. 8), o que incluiu a instalação de paraciclos pela cidade, atividades educativas e a 
publicação de um almanaque ilustrado com conteúdo específicos sobre a bicicleta e como ela é utilizada em Fortaleza.

Além disso, foi identificado que outras secretárias que tem relação com o tema como a de Meio Ambiente e Urbanismo (SEUMA) e a de Infraestrutura (SEINF) são classificadas como menos propensas ao diálogo e, no caso da segunda, ainda dominada por uma concepção rodoviarista. Algumas críticas foram apontadas para a AMC e para a ETUFOR (Empresa municipal de transporte urbano de fortaleza) sendo ambas classificadas como inertes e pouco efetivas (informação verbal) ${ }^{3}$.

Dentro do pesquisado, apontamos sobretudo dois entraves para políticas públicas de ciclomobilidade.

O primeiro deles é a complexa e burocrática estrutura da administração pública municipal, o que gera desencontro de informações e dúvidas a respeito das competências dos seus órgãos. Das 23 secretarias integrantes, nenhuma é destinada exclusivamente ao tema de mobilidade urbana. Em acréscimo, os debates em torno do tema se dão de forma significativamente fragmentada perante as Secretarias da Conservação e Serviços Públicos, à qual estão ligadas a $A M C$ e a Coordenadoria de Gestão Cicloviária, Secretaria de Infraestrutura, Secretaria de Urbanismo e Meio Ambiente, Secretaria de Cidadania e Direitos Humanos e o Instituto de Planejamento de Fortaleza (IPLANFOR).

O segundo entrave consiste no fato de que, paralelo aos debates em ciclomobilidade, a Prefeitura de Fortaleza persiste em realizar vultosos investimentos em modais rodoviaristas, o que inclui túneis e viadutos. Enquanto o Plano Diretor Cicloviário Integrado prevê investimento no importe de R\$ 52 milhões de reais até 2030 (FORTALEZA, 2014, p. 186), o aporte financeiro em obras como da "Nova Avenida Aguanambi" chega a impressionantes R\$̣ 95 milhões de reais (FORTALEZA, 2016), além da previsão de inúmeras intervenções rodoviárias em outras regiões da cidade, o que evidencia uma longa batalha para o cicloativismo na capital alencarina.

\footnotetext{
${ }^{3}$ Fornecida por Felipe Alves na Formação em ciclomobilidade da Ciclovida em 20 de fevereiro de 2016, Fortaleza, Ceará.
} 


\section{CONSIDERAÇÕES FINAIS}

A partir da pesquisa desenvolvida e dos fatos apresentados, podemos elencar alguns pontos fundamentais à título de conclusão.

Cumpre reconhecer os avanços no campo jurídico que implicam um compromisso legal com o avanço na gestão democrática da política urbana de nossas cidades, havendo ampla legislação a esse respeito. Contudo, verifica-se que apenas mediante o engajamento político dos movimentos e a pressão exercida pelos mesmos é que tais mecanismos passam a ser efetivamente estruturados e operantes.

Especificamente no caso da política de mobilidade urbana de Fortaleza, constata-se que antes do cicloativismo inexistiam políticas públicas direcionadas para a ciclomobilidade. Não obstante, com o avanço desses movimentos, seja por meios formais ou não, constatou-se que essa temática foi inserida no âmbito da administração pública municipal, embora ainda enfrente muitas dificuldades.

Pontua-se, igualmente, a diversidades de reinvindicações e estratégias do cicloativismo em Fortaleza, devendo-se reconhecer suas múltiplas formas de articulação para a compreensão das razões e objetivos de cada grupo, não se podendo incorrer em perigosas generalizações.

Por fim, vislumbra-se dificuldades do diálogo e da gestão democrática da política de mobilidade de nossa cidade. Apesar dos sensíveis avanços, a burocracia pública, a confusa repartição de competências, a tentativa de criminalização de algumas práticas e uma cultura rodoviarista ainda representam desafios para mudar tal realidade.

\section{REFERÊNCIAS}

"BICICLETA FANTASMA" É COLOCADA...Cnews, Fortaleza, 04 mar. 2013. Disponível em: <http://cnews.com.br/cnews/noticias/30390/bicicleta_fantasma_e_colocada_para_lembr ar_vitima_de_acidente_na_av_santos_dumont>. Acesso em: 07 mar. 2016.

BIKE ANJO. Projetos. 24 jan. 2016. Disponível em: < http://bikeanjo.org/projetos/eba/>. Acesso em: 07 mar. 2016. 
BOMFIM, Zulmira Áurea Cruz. Cidade e afetividade: Estima e construção dos mapas de Barcelona e São Paulo. Fortaleza: UFC, 2010.

BONAVIDES, Paulo. Ciência política. 18. ed. São Paulo: Malheiros, 2011.

CARTA DE COMPROMISSO COM A MOBILIDADE POR BICICLETA DE FORTALEZA. 2012. Disponível em: <http://216.59.16.201:8080/sapl/sapl_documentos/materia/11670_texto_ integral> Acesso em 07 mar. 2016.

CARVALHO FILHO, José dos Santos. Comentários ao Estatuto da Cidade. 3. ed. Rio de Janeiro: Lumem Juris, 2009.

CASTELLS, Manuel. Redes de indignação e esperança: movimentos sociais na era da internet. Tradução Carlos Alberto Medeiros. Rio de Janeiro: Zahar, 2013.

CICLANAS - Mulheres no trânsito de Fortaleza. Página inicial. Facebook. Disponível em: <https://www.facebook.com/ciclanas/?fref=ts> Acesso em 06 de mar. 2013.

CICLANAS - Mulheres no trânsito de Fortaleza. Sobre duas rodas: caminhos para emancipação feminina. 15 set. $2015 . \quad$ Disponível em <https://www.youtube.com/watch?v=Wp0iunEu1|4>. Acesso 07 mar 2016.

CICLOVIDA. Página inicial. Facebook. Disponível em <https://www.facebook.com/CiclovidaFortaleza/?fref=ts> Acesso em 06 de mar. 2013.

CICLOVIDA. Estatuto social da associação dos ciclistas urbanos de Fortaleza. Fortaleza, 2013.

COLETIVA PINTA CICLOFAIXAS EM RUAS DA ALDEOTA. O povo. Fortaleza, 29 set 2014. Disponível em: <http://www.opovo.com.br/app/fortaleza/2014/09/29/noticiafortaleza, 3322552/coletivo-pinta-ciclofaixa-em-ruas-da-aldeota.shtml> Acesso em: 06 mar. 2016.

CONHEÇA O MASSA CRÍTICA, COLETIVO RESPONSÁVEL POR INTERVENÇÕES QUE DESPERTAM AMOR E ÓDIO EM FORTALEZA. Tribuna do Ceará. Fortaleza, 24 set de 2015. Disponível em <http://tribunadoceara.uol.com.br/noticias/mobilidadeurbana/conheca-omassa-critica-coletivo-responsavel-por-intervencoes-que-despertam-amor-e-odio-emfortaleza/>. Acesso em: 06 mar. 2016.

EMBAIXADA HOLANDESA DE CICLISMO. Os peritos mundiais de ciclismo. Fundação Embaixada Holandesa de Ciclismo. Disponível em <https://www.dutchcycling.nl/library/file/DCE\%20Brochure\%20Portugese.pdf>. Acesso em: 06 mar. 2016.

FORTALEZA. Plano diretor cicloviário integrado. Disponível em: <http://www.fortaleza.ce.gov.br/sites/default/files/seinf/PDCIFORTALEZA.pdf>. Acesso em: 06 mar. 2016.

FORTALEZA. Prefeito Roberto Cláudio assina ordem de serviço para obras na Avenida Aguanambi. Site oficial, 16 jan 2016. Disponível em: <http://www.fortaleza.ce.gov.br/noticias/mobilidade/prefeito-roberto-claudio-assinaordem-de-servico-para-obras-na-avenida-aguanambi>. Acesso em: 06 mar. 2016.

GHOST BIKES. Disponível: < http://ghostbikes.org/>. Acesso em: 06 mar. 2016.

GRUPO PINTA CICLOFAIXA NA ANA BILHAR. Diário do Nordeste, Fortaleza, 04 ago., 2013. Disponível em: <http://diariodonordeste.verdesmares.com.br/cadernos/cidade/grupopinta-ciclofaixa-na-ana-bilhar-1.383634>. Acesso em: 06 mar. 2016. 
INTITUTO DE PLANEJAMENTO DE FORTALEZA (IPLANFOR). Planejamento participativo: por uma Fortaleza de oportunidades, mais justa, bem cuidada e acolhedora. Série Fortaleza 2040, ano I, n.1, 2014.

INSTITUTO DE PESQUISA E ESTRATÉGIA ECONÔMICA DO CEARÁ (IPECE). Perfil municipal de Fortaleza: tema XII: Mobilidade Urbana. Série IPECE Informa, n. 52, 2013.

LOPES FILHO, Juraci Mourão. A democracia na Administração Público e no Direito Administrativo Brasileiro. Revista Opinião Jurídica, Fortaleza, v. 12, p. 190 - 210, 2010.

MASSA CRÍTICA. Ação direita. Publicado em 15 mar. 2015. Disponível em: <https://www.youtube.com/watch?v=utluodAkiYk>. Acesso em: 06 mar. 2016.

MASSA CRÍTICA. Página inicial. Facebook. Disponível em <https://www.facebook.com/MassaCriticaFortaleza/?fref=nf>. Acesso em: 06 mar. 2016. MASSA CRÍTICA DE FORTALEZA CRIA PRAÇA DO CICLISTA. Vá de bike, 8 out. 2014. Disponível em: <http://vadebike.org/2014/10/praca-do-ciclista-fortaleza-primeiro-demaio/>. Acesso em: 07 mar. 2016.

Return of the Scorcher. Direção: Ted White; Produção: Ted White. 1992. 28 min. Color.

SAKURABA. Celso. Mês da mobilidade 2015: Fortaleza. Disponível em: <https://www.catarse.me/mobilidade2015> Acesso em: 07 mar. 2016.

SANTOS, Boaventura de Sousa. Refundación del estado en América Latina: perspectivas desde una epistemología del sur. Lima: Instituto Internacional de Derecho y Sociedad, 2010.

SANTOS, Milton. A natureza do espaço: técnica e tempo, razão e emoção. 4 ed. São Paulo: EDUSP, 2006.

SANTOS, Milton, SILVEIRA, Maria Laura. O Brasil: território e sociedade no início do século XXI. 9 ed. Rio de Janeiro: Record, 2006.

SAULE JÚNIOR, Nelson. Direito urbanístico: vias jurídicas das políticas urbanas. Porto Alegre: Sergio Antônio Fabris, 2007.

SILVA, José Afonso da. Direito urbanístico brasileiro. 6. ed. São Paulo: Malheiros, 2010.

SECRETARIA DE CIDADANIA E DIREITOS HUMANOS (SCDH). Cidadania sustentável: para viver a cidade. Fortaleza. 2015

SOARES, André Geraldo et al. (org.). A bicicleta no brasil. São Paulo: D. Guth, 2015.

SWOV - INSTITUTE FOR ROAD SAFETY RESEARCH. Road fatalities in the Netherlands. Haia, Holanda, abr. 2015. Disponível em: <https://www.swov.nl/rapport/Factsheets /UK/FS_Road_fatalities.pdf> Acesso em: 06 mar. 2016.

VERSODEPEQUEBRADO. Pintura da ciclofaixa da Ana Bilhar. Disponível em: <www.youtube.com/watch?v=Roq26AWROZk>. Acesso em: 06 mar. 2016. 
CARVALHO, Harley Sousa de; FREITAS, Rafael Mesquita Ferreira. Democracia e resistência na gestão urbana de Fortaleza: um olhar a partir do cicloativismo. RBSD Revista Brasileira de Sociologia do Direito, v. 4, n. 1, p. 161-181, jan./abr. 2017.

Recebido em: 26/10/2016

Aprovado em: 10/01/2017 